\title{
HISTORICAL AND CONTEMPORARY CLIMATE LEGACY OF THE LARGE-SCALE DISTRIBUTIONAL PATTERNS OF PLANT RICHNESS ACROSS DIFFERENT TAXONOMIC LEVELS: AN ASSESSMENT OF PROTECTED AREAS IN CHINA
}

\section{EL LEGADO CLIMÁTICO HISTÓRICO Y CONTEMPORÁNEO DE LOS PATRONES DE DISTRIBUCIÓN A GRAN ESCALA DE LA RIQUEZA VEGETAL EN DIFERENTES NIVELES TAXONÓMICOS: UNA EVALUACIÓN DE LAS ÁREAS PROTEGIDAS EN CHINA}

\author{
CHUN-JING WANG ${ }^{1,2,3,4}$, AND JI-ZHONG WAN ${ }^{1,4^{*}}$
}

\author{
${ }^{1}$ State Key Laboratory of Plateau Ecology and Agriculture, Qinghai University, Xining, China \\ ${ }^{2}$ College of Agriculture and Animal Husbandry, Qinghai University, Xining, China \\ ${ }^{3}$ School of Nature Conservation, Beijing Forestry University, Beijing, China \\ ${ }^{4}$ Departamento de Ecología, Facultad de Ciencias Biológicas, Pontificia Universidad Católica de Chile, Santiago, Chile \\ *Corresponding author: wan1276@163.com
}

\begin{abstract}
Background: Historical and contemporary climates may shape the distributional patterns of plant species richness across different scales. However, few studies have focused on the effects of historical and contemporary climate changes on the distributional patterns of plant richness in Chinese protected areas across different taxonomic levels.

Hypotheses: Historical and contemporary climates can have an important legacy effect on the large-scale distributional patterns of plant richness across different taxonomic levels.

Studied species: Vascular plants.

Study site: China.

Method: We used data on plant richness at the family, genus, and species levels from Chinese protected areas and applied regression modelling to explore the relationships between climate change and plant richness among vascular, fern, seed, gymnosperm, and angiosperm plants based on paleoclimate (Last Glacial Maximum; LGM, ca. 22,000 years ago) and contemporary climate data.

Results: The large-scale distributional patterns of plant richness could be predicted across different taxonomic levels on the basis of paleoclimate and contemporary climate data. Specifically, historical and contemporary climate variables were found to better correlate with fern plant richness than seed plant richness. For seed plants, the explanatory power of historical and contemporary climate variables was found to be stronger for the richness of gymnosperms than for the richness of angiosperms.

Conclusions: The distributional pattern of plant richness could be predicted across different taxonomic levels after including paleoclimate (LGM, ca. 22,000 years ago) and contemporary climate data from China. Our study could support the effectiveness of the management of protected areas in China.
\end{abstract}

Key words: China, climate legacy, conservation, paleoclimate, plant diversity, taxonomic level, vascular plants.

\section{Resumen}

Antecedentes: Los climas históricos y contemporáneos contribuyen a conformar el patrón de la distribución de la riqueza de especies de plantas a diferentes escalas. Sin embargo, muy pocos estudios se han concentrado en entender los efectos de los cambios históricos y contemporáneos del clima en el patrón de la distribución de la riqueza de plantas en diferentes niveles taxonómicos en China.

Hipótesis: Los climas históricos y contemporáneos pueden tener un importante efecto de legado en los patrones de distribución a gran escala de la riqueza de plantas a diferentes niveles taxonómicos.

Especies de estudio: Plantas vasculares.

Sitio de estudio: China.

Métodos: Empleando datos de reservas naturales chinas y modelado de Regresión Ponderada Geográficamente aplicada junto con el método de Mínimos Cuadrados Ordinarios, utilizamos la información de riqueza de plantas a nivel de familia, género y especies para explorar las relaciones entre el cambio climático histórico y contemporáneo, y la riqueza de plantas a nivel de familia, género y especie entre diferentes grupos de plantas vasculares, helechos, semillas, gimnospermas y angiospermas.

Resultados: En comparación con las plantas de semilla, los climas históricos y contemporáneos predicen mejor la riqueza de helechos. Para las plantas con semillas, los poderes explicativos de los climas históricos y contemporáneos son más fuertes para la riqueza de gimnospermas que para la de angiospermas.

This is an open access article distributed under the terms of the Creative Commons Attribution License CCBY-NC (4.0) international. https://creativecommons.org/licences/by-nc/4.0/ 
Conclusiones: El patrón de distribución de la riqueza de plantas se pueden predecir a diferentes niveles taxonómicos utilizando datos paleoclimáticos y de clima contemporáneo en China.

Palabras clave: China, diversidad vegetal, legado climático, nivel taxonómico, paleoclima, plantas vasculares.

Plant richness can deeply affect ecosystem structure and function (Tilman et al. 1997). Both the historical and contemporary climate can influence the large-scale geographic patterns of plant richness (Kreft \& Jetz 2007, Normand et al. 2011, Sandel et al. 2011, Svenning et al. 2015, Liu et al. 2018). Time lags in the legacy effects of historical climates on biodiversity may vary widely across different plant species (Normand et al. 2011, Svenning et al. 2015, Shrestha et al. 2018). These time lags may influence the response of the distributional and richness patterns of plant species to climate change via several mechanisms (e.g., diversification, lineage adaptation, range shifts, population buildup, and physiological responses; Svenning et al. 2015). Contemporary plant richness is to some degree the product of diversification within the Cenozoic (Colinvaux \& De Oliveira 2001, Svenning et al. 2015), and in this way, paleoclimates may influence the diversification of plants and shape the current distribution of plant richness at large scales (Svenning et al. 2015).

Different studies (e.g., Svenning 2003, Svenning \& Skov 2007, Fang et al. 2012, Svenning et al. 2015, Liu et al. 2018) have shown that contemporary climates are the main predictors of large-scale distributional patterns of plant richness. For example, the mean annual temperature (MAT) and mean annual precipitation (MAP) in recent years have been shown to influence the contemporary distributional patterns of plant richness in China (Wang et al. 2010, 2012, Yang et al. 2014, Wang et al. 2017). European plant richness is one of the best-known examples in which regional distributions of plant richness are strongly affected by contemporary temperature and precipitation as well as by late Quaternary glacial-interglacial climates (Kreft \& Jetz 2007, Svenning \& Skov 2007, Fang et al. 2012, Svenning et al. 2015). The physiological responses of plant species to historical climates may be delayed, and contemporary climates may also affect the distribution of plant richness (Svenning \& Skov 2007, Svenning et al. 2015).

The understanding of the effects of historical and contemporary climate on plant richness can provide new insights into the evolution of plant species at large scales. Previous studies (e.g., Svenning 2003, Wang et al. 2010, 2012, Yang et al. 2014, Svenning et al. 2015, Liu et al. 2018) have evaluated the effects of historical and contemporary climates on plant richness at the species level. However, to fully understand these effects, it is important to evaluate them in terms of large-scale distributional patterns of plant richness at different taxonomic levels, from family to species, and from ferns to angiosperms.

The evaluation of biodiversity at the family and genus levels can indicate the evolutionary distinctiveness of a given set of species and provide more information on the evolutionary processes affecting plant species richness across different spatial and temporal scales than studies only focusing on the species level (O'Brien et al. 1998, Pimm \& Joppa
2015, Qian \& Ricklefs 2007, Huang et al. 2016). In addition, phylogenetic endemism and biogeography may indicate the evolutionary distinctiveness of plants at large scales (Prinzing 2001, Huang et al. 2016). The large-scale patterns of biodiversity at the family and genus levels can be accurately used to identify instances of phylogenetic endemism and geographical concentrations related to the evolutionary history of plants (O'Brien et al. 1998, Qian \& Ricklefs 2007, Huang et al. 2016, Millar et al. 2017).

The climatic niche development of higher plants across different taxonomic levels (i.e., species, family, and genus) differs considerably at large scales (O'Brien et al. 1998, Pimm \& Joppa 2015). Hence, dissimilarity in the large-scale distributional patterns of plant richness may exist across different taxonomic levels. Furthermore, previous studies have identified different legacy effects of climate on the largescale distributional patterns of plant richness in non-seed and seed plants (Peppe et al. 2014, Boyce \& Lee 2017, Xu et al. 2018). Non-seed plants may be more sensitive to the velocity of climate change than seed plants due to their different reproduction and dispersal characteristics (Peppe et al. 2014, $\mathrm{Xu}$ et al. 2018). Lu et al. (2018) explored the evolutionary history of the angiosperm flora of China at the species, family, and genus levels and identified areas of high species richness and phylogenetic diversity. However, we need to explore the differences in the effects of historical and contemporary climates on the large-scale distributional patterns of plant richness across different taxonomic levels.

Here, we tested the following hypotheses: 1) historical and contemporary climates can affect the large-scale distributional patterns of plant richness and 2) the effects of historical and contemporary climates on plant richness vary across different plant groups and taxonomic levels. To test the abovementioned hypotheses, we used data on plant richness from Chinese protected areas at the family, genus, and species levels and explored the relationships between historical and contemporary climate and plant richness based on different groups of vascular, fern, seed, gymnosperm, and angiosperm plants. The testing of these two hypotheses will allow our study to contribute to the development of effective strategies for the conservation of plant diversity in protected areas in China.

\section{Materials and methods}

Plant richness data. Data on plant richness, including that of ferns (non-seed) and seed plants, including gymnosperms and angiosperms, were collected and organized across different taxonomic levels (i.e., the total number of families, genera, and species) from published records regarding natural reserves in China. The list of published records was provided by the study by Wang et al. (2017, Figure 1). Based on the published records, we extracted data on the plant 


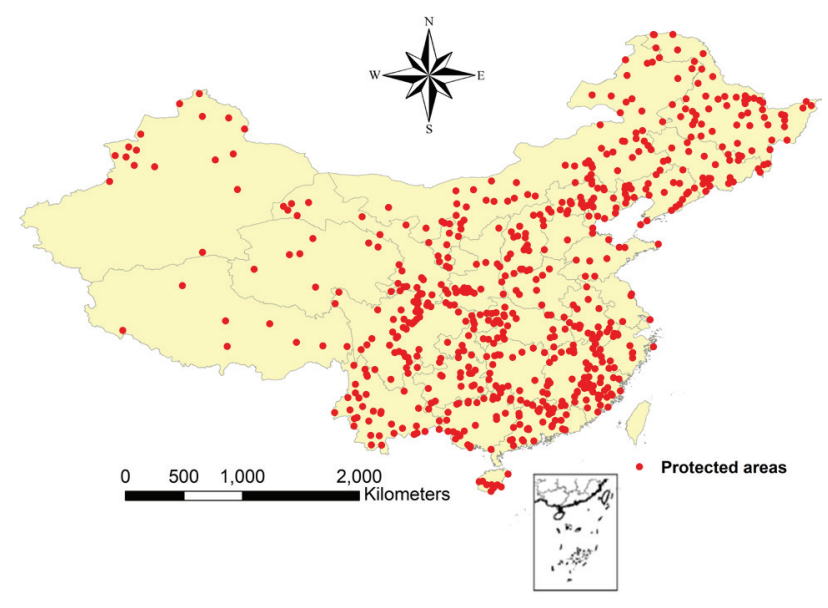

Figure 1. Distribution of the protected areas in China used in our analysis.

taxon richness found in core areas of protected areas. In China, the goal of core zones of protected areas is to protect relatively undisturbed natural vegetation, which has a long, uninterrupted history in this region, and the associated data thus represent an ideal dataset of plant richness (Tang et al. 2010, Zhang et al. 2017).

Based on previous studies (e.g., Huang et al. 2016, Feng et al. 2017, Zhang et al. 2017, Liu et al. 2018), we transposed the plant richness data from the core zones of the protected areas into grid data at a spatial resolution of 10 arc minutes (c. $16 \times 16 \mathrm{~km}$ ). Different groups of vascular plants (fern, gymnosperm, and angiosperm plants) were analysed in our study, as vascular plants include non-seed plants (ferns) and seed plants (gymnosperms and angiosperms). For the accurate nomenclature of scientific names, we followed the Plant List (www.theplantlist.org) and compared the lists of families, genera, and species based on The Plant List (http://www.theplantlist.org) and the Flora of China (http://frps.iplant.cn/) to identify the plant groups in our study. We deleted the wrong data on plant richness of protected areas. We found that the effect of the area of a nature preserve on plant richness could be excluded from further analyses because there was no significant relationship between reserve size and plant richness across the different taxonomic levels (i.e., the total number of families, genera, and species) based on linear regression modelling $(P>0.05)$. Finally, data from protected areas were obtained (detailed information in the Supplemental data and Figure 1).

Climate data. The MAT and MAP were used to assess the legacy effects of climate on the large-scale distributional pattern of plant richness (e.g., Svenning et al. 2015, Feng et al. 2017, Blonder et al. 2018). Feng et al. (2017) showed that historical and contemporary MAT and MAP could influence plant endemism in China. We downloaded the grid maps of historical and contemporary MAT and MAP at a spatial resolution of 10 arc minutes (ca. $16 \times 16 \mathrm{~km}$ ) from the WorldClim database (http://www.worldclim.org/). The extremely dry and cold climate during the Last Glacial Maximum (LGM; approximately 22,000 years ago) excluded tropical forests from China and caused other strong vegetational changes (Wang et al. 2012, Feng et al. 2017). Paleoclimate (i.e., the LGM) has been shown to be the main driver of plant richness at large scales (e.g., Kreft \& Jetz 2007, Svenning \& Skov 2007, Fang et al. 2012, Svenning et al. 2015). The Holocene has not been long enough to have allowed speciation in most cases (Lister 2004, Svenning et al. 2015); hence, we used average climate data from 1950-2000 AD to represent the contemporary scenario and paleoclimate data (i.e., the LGM) for the historical scenario. Paleoclimate data in regard to MAT and MAP were obtained from the CCSM4 general circulation model (http://www.cesm.ucar.edu/models/ccsm4.0/). The CCSM4 model consists of a coupled atmospheric, oceanic, and sea ice model with noninteractive vegetation and an atmospheric resolution of 10.0 arc minutes. The model is driven by variations in orbital configuration, greenhouse, ice-sheet topography, and coincident sea level changes and bathymetry for paleoclimates (Lawrence \& Oleson 2012). The paleoclimate data have the same coordinate system and resolution as the contemporary climate data. A paired-sample $t$-test coupled with a Bonferroni adjustment was used to evaluate the differences between the paleoclimate data and contemporary climate data across all the protected areas. The paired-sample $t$-test was conducted in JMP version 11.0 (SAS Institute Inc., Cary NC).

Data analysis. Spatial autocorrelation in ecological data can inflate Type I errors in statistical analyses (Diniz-Filho et al. 2003). Hence, we used Moran's I coefficient calculated on the basis of a distance matrix to assess the spatial autocorrelation in plant richness across the different taxonomic levels (i.e., the total number of families, genera, and species) (Diniz-Filho et al. 2003). The default settings were used in SAM 4.0 (Rangel et al. 2010), and the default number of distance classes was 17 with an equal number of pairs between different protected areas according to the available plant richness data (Rangel et al. 2010). Pearson correlation coefficients were used to assess the correlations in plant richness between the different groups (i.e., vascular, fern, seed, gymnosperm, and angiosperm) and taxonomic levels (i.e., family, genus, and species) across the protected areas. The analysis of Pearson correlation coefficients was conducted in JMP version 11.0 (SAS Institute Inc., Cary NC).

Then, we used geographically weighted regression (GWR) coupled with the ordinary least squares (OLS) method to evaluate both the historical and contemporary climates and identify the large-scale distributional patterns of plant richness (Brunsdon et al. 1996, Mellin et al. 2014, Xu et al. 2016). GWR is a local form of linear regression that is used to spatially model varying relationships based on the assessment of nonstationarity and the effects of spatial scale on ecological data (Brunsdon et al. 1996, Mellin et al. 2014). Previous studies (e.g., Foody 2004, Eiserhardt et al. 2011, Mellin et al. 2014) have shown that GWR is useful in the investigation of spatially varying biodiversity-environment 
relationships because spatial autocorrelation and heterogeneity exist in ecological data. The variables pertaining to the historical and contemporary climates (including MAT and MAP) were regarded as explanatory variables, and plant richness was regarded as the dependent variable across the different groups of vascular, fern, seed, gymnosperm, and angiosperm plants. The specific settings for the GWRs were as follows: 1) the spatial function of the GWR was Gaussian; 2) the adaptive kernel was $10 \%$ neighbours; and 3) optimization to minimize the AICc (corrected Akaike information criterion) was used for all bandwidths (Brunsdon et al. 1996, Eiserhardt et al. 2011, Xu et al. 2016). The GWR analysis was conducted with SAM 4.0 (Rangel et al. 2010).

The correlation coefficients $(r)$ and $P$-values from the GWR and OLS analyses were used to assess the associations between the historical and contemporary climates (including MAT and MAP) and plant richness. We used the adjusted $R^{2}$ adj $(\%)$ from the GWR to determine the explanatory power of the historical and contemporary climate in regard to the large-scale distributional pattern of plant richness (Blonder et al. 2018, Liu et al. 2018). Meanwhile, the $R^{2}{ }_{a d j}(\%)$ of the OLS analysis was used to test the relationships between the historical and contemporary climates and plant richness. Then, we compared the correlation coefficient $(r)$ and $R^{2}$ adj (\%) of the GWR with the OLS analysis to test whether the GWR performed better than the OLS method (Brunsdon et al. 1996).

Finally, we used OLS to determine the best predictors of the large-scale distributional patterns of plant richness at different taxonomic levels (i.e., the total number of species, families, and genera) across the vascular, fern, seed, gymnosperm, and angiosperm plant groups in independent analyses (Nagelkerke 1991, Liu et al. 2018). The adjusted $R_{\text {adj }}^{2}(\%)$ from the OLS analysis was used to determine the explanatory power of climate in regard to the large-scale distributional patterns of plant richness. We conducted the OLS analysis in JMP 10.0 (SAS Institute Inc., Cary, NC).

\section{Results}

The ranges of vascular plant richness were 11-257, 30-1372, and 45-4543 at the family, genus, and species levels, respectively (Table 1). The average vascular plant richness was 132, 506, and 1117 from the family to species level (Table 1). Specifically, the average fern species richness was 20,40, and 87 at the family, genus, and species levels, respectively, and the average seed plant species richness was 112, 467, and 1027 at the family, genus, and species levels, respectively (Table 1). The average family, genus, and species richness values were 4 (ranging from 1 to 10), 8 (ranging from 1 to 33 ) and 14 (ranging from 1 to 102) for gymnosperms and 108 (ranging from 22 to 203), 460 (ranging from 52 to 1,244) and 1,024 (ranging from 65 to 3,931 ) for angiosperm plants, respectively (Table 1 ).

The MAP and MAT in the contemporary climate were significantly higher than those in the paleoclimate (pairedsample t-test; $P<0.05)$. Specifically, the average historical MAT was $5.1^{\circ} \mathrm{C}$ (ranging from $-14.8^{\circ} \mathrm{C}$ to $21.9^{\circ} \mathrm{C}$ ), and
Table 1. Basic description of plant richness in protected areas in China

\begin{tabular}{lcccc}
\hline & Mean & SD & Max. & Min. \\
\hline Vascular plant family & 132 & 58.0 & 257 & 11 \\
Vascular plant genus & 506 & 267.4 & 1372 & 30 \\
Vascular plant species & 1117 & 773.2 & 4543 & 45 \\
Fern family & 20 & 13.4 & 50 & 1 \\
Fern genus & 40 & 31.8 & 127 & 1 \\
Fern species & 87 & 92.0 & 594 & 1 \\
Seed plant family & 112 & 44.9 & 210 & 22 \\
Seed plant genus & 467 & 234.1 & 1251 & 53 \\
Seed plant species & 1027 & 689.2 & 3949 & 43 \\
Gymnosperm family & 4 & 2.4 & 10 & 1 \\
Gymnosperm genus & 8 & 5.9 & 33 & 1 \\
Gymnosperm species & 14 & 12.0 & 102 & 1 \\
Angiosperm family & 108 & 42.6 & 203 & 22 \\
Angiosperm genus & 460 & 229.0 & 1244 & 52 \\
Angiosperm species & 1024 & 672.2 & 3931 & 65 \\
\hline
\end{tabular}

the contemporary MAT was $10.1^{\circ} \mathrm{C}$ (ranging from $-8.9{ }^{\circ} \mathrm{C}$ to $25.5^{\circ} \mathrm{C}$; Table 2 ). The average historical MAP was 830.7 $\mathrm{mm}$ (ranging from $17 \mathrm{~mm}$ to $2232 \mathrm{~mm}$ ), and the contemporary MAP was $952.4 \mathrm{~mm}$ (ranging from $26 \mathrm{~mm}$ to 2,262 mm; Table 2).

Based on the Moran's I coefficients, the spatial autocorrelation in the plant richness data was low across the different taxonomic levels (most Moran's I coefficients were $<0.200$ or $>-0.200$; Figure 2). We found that there were significant correlations in plant richness among the different taxonomic levels (i.e., families, genera, and species; $P<0.05$; Table 3). Additionally, a significant relationship of plant richness among the different vascular, fern, seed, gymnosperm, and angiosperm plant groups could be detected $(P<0.05$; Table $3)$. The correlation coefficients were the largest $(0.9979 ; P$ $<0.05$ ) between seed and gymnosperm plants at the family level, between vascular and seed plants at the genus level (0.9979; $P<0.05)$, and between seed and angiosperm plants $(0.9979 ; P<0.05)$ at the species level (Table 3$)$.

All the correlation coefficients in the GWR between the historical and contemporary climate variables (including MAT and MAP) and plant richness were higher than 0.49 $(P<0.001)$, and those in the OLS analysis were higher than 0.20 across the different taxonomic levels $(P<0.001$; Table 4). Values of $R^{2}$ adj $(\%)$ represent the adjusted $R_{\text {adj }}^{2}(\%)$ values obtained from the GWR and OLS analyses conducted to determine the explanatory power of historical and contemporary climate variables on the large-scale distributional pattern of plant richness. Based on $R^{2}{ }_{a d j}$, the GWR showed better modelling performance than the OLS analysis, indicating that both historical and contemporary climate coupled with spatial autocorrelation can explain the distributional patterns of plant richness at large scales (Table 4). 
Table 2. Basic description of mean annual temperature (MAT; ${ }^{\circ} \mathrm{C}$ ) and mean annual precipitation (MAP; $\mathrm{mm}$ ) in protected areas in China

\begin{tabular}{lcccc}
\hline & Mean & SD & Max. & Min. \\
\hline Historical MAT & 5.3 & 8.2 & 21.9 & -14.8 \\
Historical MAP & 842.0 & 534.7 & 2232 & 17 \\
Contemporary MAT & 10.3 & 7.1 & 25.5 & -8.9 \\
Contemporary MAP & 962.6 & 520.7 & 2262 & 26 \\
\hline
\end{tabular}

The following results regarding the $R_{\text {adj }}^{2}$ value were obtained from the GWR. The combination of historical and contemporary climate could explain the richness of vascular plant families, genera, and species $\left(R^{2}{ }_{a d j}=25.8 \%, 26.1 \%\right.$, and $26.4 \%$, respectively; $P<0.001$; Table 4 ), and both historical and contemporary climate had the strongest explanatory power in regard to the richness of fern genera and species $\left(R_{a d j}^{2}=34.6 \%\right.$ and $37.6 \%$, respectively; $P<0.001$; Table 4). The historical and contemporary MAT and MAP had the strongest explanatory power in regard to richness at the family level $(P<0.001$; Table 4$)$ but the smallest explanatory power in regard to species richness based on the $R^{2}{ }_{a d j}(\%)$ from the OLS analysis $(P<0.001$; Table 4$)$.

Historical MAT explained plant richness at different taxonomic levels in a better way than contemporary MAT, and this explanatory power of the MAP was opposite to that of the MAT across the different taxonomic levels (Figure $3)$. Furthermore, the explanatory power of the contemporary MAP was the strongest for plant richness at the family, genus, and species levels (Figure 3). With the exception of historical and contemporary MAT, historical and contemporary climate variables better explained fern richness than seed plant richness across all the taxonomic levels (Figure 3). Regarding gymnosperm and angiosperm plants, the explanatory power of historical and contemporary climates was stronger for gymnosperm plant richness than angiosperm plant richness across all taxonomic levels (Figure 4). Furthermore, the

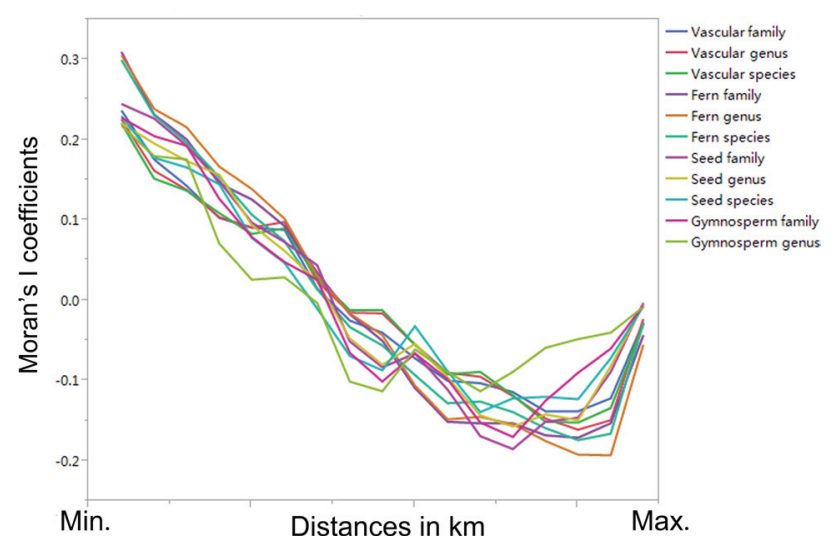

Figure 2. Moran's I coefficients across different taxonomic levels (i.e., families, genera, and species) and groups (i.e., vascular, fern, seed, gymnosperm, and angiosperm plants). historical and contemporary MAP had the strongest explanatory power in regarding to angiosperm plant richness at the family level $\left(R_{a d j}^{2}>60.0 \% ; P<0.001\right.$; Figure 4$)$.

\section{Discussion}

Our results showing that the average vascular plant richness was 132 (ranging from 11 to 257), 506 (ranging from 30 to 1,372 ), and 1,117 (ranging from 45 to 4,543 ) at the family, genus, and species levels, respectively, and that the plant richness was also high for fern, seed, gymnosperm, and angiosperm plants in protected areas of China (detailed information in Table 1) indicate that the protected area network in China has rich plant resources. In particular, Chinese protected areas have a high richness of angiosperm plants (Table 1). Hence, the ability of protected areas to conserve plant richness is strong in China.

We found that the contemporary climate variables (i.e., MAP and MAT) were significantly higher than those for the paleoclimate (paired-sample $t$-test; $P<0.05$; Table 2), and previous studies (e.g., Araújo et al. 2011, Keppel et al. 2015, Wan et al. 2018) have shown that climate change has a high potential to threaten the effectiveness of protected areas in terms of conserving plant diversity at large scales. The exploration of the legacy effects of climate on the largescale distributional patterns of plant richness is key for plant diversity conservation in protected areas in China. Based on the database of plant richness data from Chinese protected areas (with low spatial autocorrelation in plant richness data across different taxonomic levels; Figure 2), we examined the legacy effects of historical and contemporary climate on the large-scale distributional patterns of plant richness across different taxonomic levels.

The results of our GWR for both the historical and contemporary climate show significant explanatory power in terms of plant richness in China across various taxonomic levels (Table 4; Figures 3, 4), which hints that historical and contemporary climate affect the large-scale distributional patterns of plant richness across various taxonomic levels. Interestingly, the MAT was more important in the historical climate scenario than the present day scenario; however, the opposite was true of MAP according to the results of the explanatory power analysis (Figures 3,4 ). The explanatory power of the historical and contemporary climate variables was higher at the family and genus levels and decreased at the species level based on the results regarding $R^{2}$ (Figures 3, 4). O'Brien et al. (1998) showed that the realized distributional limits of families and genera (unlike species) could be constrained by year-round or seasonally high ambient energy and by seasonally low ambient energy regardless of the water regime. Therefore, the historical and contemporary climate can better explain family and genus richness than species richness. Furthermore, historical and contemporary climate variables (including MAT and MAP) were found to better explain the richness of fern (non-seed) plants than that of seed plants (Figures 3, 4).

Some studies (e.g., Wang et al. 2012, Svenning \& Sandel 2013, Svenning et al. 2015) have found that both the 
Wang and Wan / Botanical Sciences 97 (3): 323-335. 2019

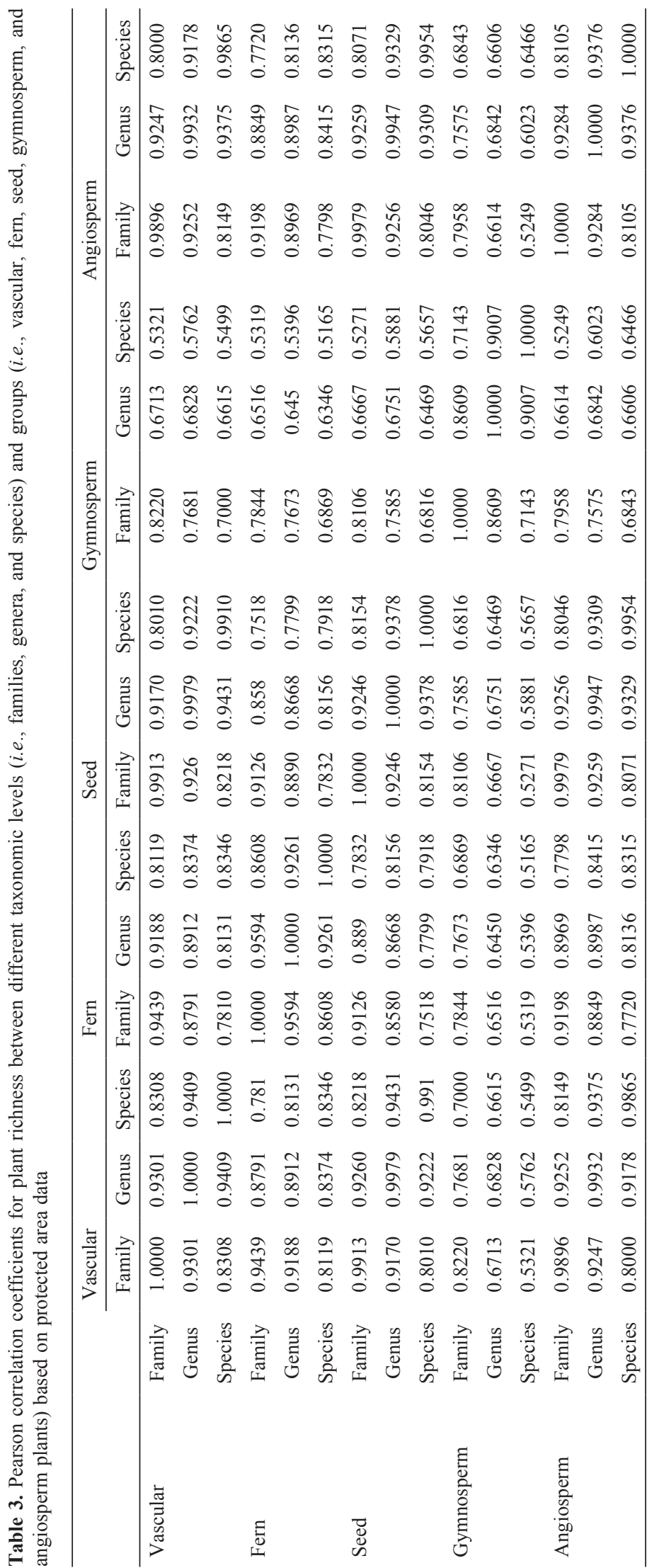


Table 4. Results of geographically weighted regression (GWR) and ordinary least squares (OLS) analysis of the effects of both historical and contemporary climate on plant richness

\begin{tabular}{|c|c|c|c|c|c|c|}
\hline & \multicolumn{3}{|c|}{ GWR } & \multicolumn{3}{|c|}{ OLS } \\
\hline & $r$ & $R^{2} \operatorname{adj}(\%)$ & $P$-value & $r$ & $R^{2} \operatorname{adj}(\%)$ & $P$-value \\
\hline Vascular plant family & 0.560 & 25.8 & $<0.001$ & 0.491 & 23.8 & $<0.001$ \\
\hline Vascular plant genus & 0.563 & 26.1 & $<0.001$ & 0.474 & 22.1 & $<0.001$ \\
\hline Vascular plant species & 0.566 & 26.4 & $<0.001$ & 0.461 & 20.9 & $<0.001$ \\
\hline Fern family & 0.624 & 33.9 & $<0.001$ & 0.552 & 30.1 & $<0.001$ \\
\hline Fern genus & 0.629 & 34.6 & $<0.001$ & 0.544 & 29.3 & $<0.001$ \\
\hline Fern species & 0.613 & 37.6 & $<0.001$ & 0.499 & 24.5 & $<0.001$ \\
\hline Seed plant family & 0.611 & 32.2 & $<0.001$ & 0.536 & 28.4 & $<0.001$ \\
\hline Seed plant genus & 0.629 & 34.6 & $<0.001$ & 0.521 & 26.8 & $<0.001$ \\
\hline Seed plant species & 0.636 & 35.6 & $<0.001$ & 0.508 & 25.5 & $<0.001$ \\
\hline Gymnosperm family & 0.586 & 28.9 & $<0.001$ & 0.512 & 25.9 & $<0.001$ \\
\hline Gymnosperm genus & 0.566 & 26.5 & $<0.001$ & 0.438 & 18.8 & $<0.001$ \\
\hline Gymnosperm species & 0.521 & 21.2 & $<0.001$ & 0.361 & 12.7 & $<0.001$ \\
\hline Angiosperm family & 0.543 & 23.7 & $<0.001$ & 0.454 & 20.3 & $<0.001$ \\
\hline Angiosperm genus & 0.567 & 26.6 & $<0.001$ & 0.453 & 20.2 & $<0.001$ \\
\hline Angiosperm species & 0.576 & 27.6 & $<0.001$ & 0.444 & 19.3 & $<0.001$ \\
\hline
\end{tabular}

This table shows the correlation coefficients $(r)$ and $P$-values of GWR and OLS analysis of the associations between historical and contemporary climate variables (including MAT and MAP) and plant richness across different taxonomic levels (i.e., family, genus, and species) based on the vascular, fern, seed, gymnosperm, and angiosperm plant groups.

historical and contemporary climate can explain large-scale distributional patterns of plant richness. However, these effects may change across different taxonomic levels depending on the MAT and MAP (Figures 3, 4). There is ample evidence showing that Quaternary climatic change shaped the current patterns of plant richness and endemism across different regions of the world (e.g., North America, Europe, and Africa; Svenning \& Skov 2007, Normand et al. 2011, Svenning et al. 2015, Barnosky et al. 2016, Cotton et al. 2016). The dynamics of plant richness may not follow the climatic equilibrium (Svenning \& Sandel 2013, Svenning et al. 2015). In addition, a shift to a new climatic equilibrium can cause time lags (Svenning \& Sandel 2013, Svenning et al. 2015). Plant species may experience a slower response to changes in temperature than to those of precipitation, and in many places, the migration of these species has shown a time lag in response to temperature changes (Svenning \& Sandel 2013, Normand et al. 2011, Svenning et al. 2015).

Plant community structure is strongly influenced by water under environmental change, and plant richness is strongly correlated with current water availability on a large scale (O'Brien 1998, O'Brien et al. 1998, Yang et al. 2011). For example, the distributional pattern of plant richness is an important link to late Cenozoic precipitation trends, and a positive correlation between the mean annual rainfall and woody plant richness can be observed in southern Africa (O'Brien 1998, O'Brien et al. 1998). Therefore, the response lags of plant richness to historical temperature and the ef- fects of current precipitation on plant richness may drive the distributional pattern of plant richness at a large scale.

Blonder et al. (2018) found that paleoclimate (i.e., MAT and MAP) is a better predictor of the spatial pattern of contemporary functional plant composition than contemporary climate predictors. The spatial pattern of contemporary functional plant composition is related to the distribution of plant richness at large scales (Petchey \& Gaston 2002, Thompson et al. 2005, White et al. 2018). Furthermore, plant species diversity may change more than functional-trait diversity because high levels of trait-based redundancy imply that the loss of a particular species should not affect ecosystem functions because of the maintenance of other species with similar traits (Díaz \& Cabido 2001, Petchey \& Gaston 2006). Relationships between functional-trait diversity and plant richness can still exist at various spatial and temporal scales (Petchey \& Gaston 2002, 2006, Kraft et al. 2015). Hence, historical MAT may have greater effects than contemporary MAT on the distributional pattern of plant richness, and contemporary MAP could also strongly affect the plant richness pattern.

The explanatory power of the historical and contemporary climate variables in regard to plant richness varied across the different taxonomic levels (Table 4; Figures 3, 4). Specifically, the historical and contemporary climate had the strongest explanatory power in terms of the family richness and the smallest explanatory power in regard to the species richness (Table 4; Figures 3, 4). The family taxonomic level can define the collective evolutionary distinctiveness of a set 

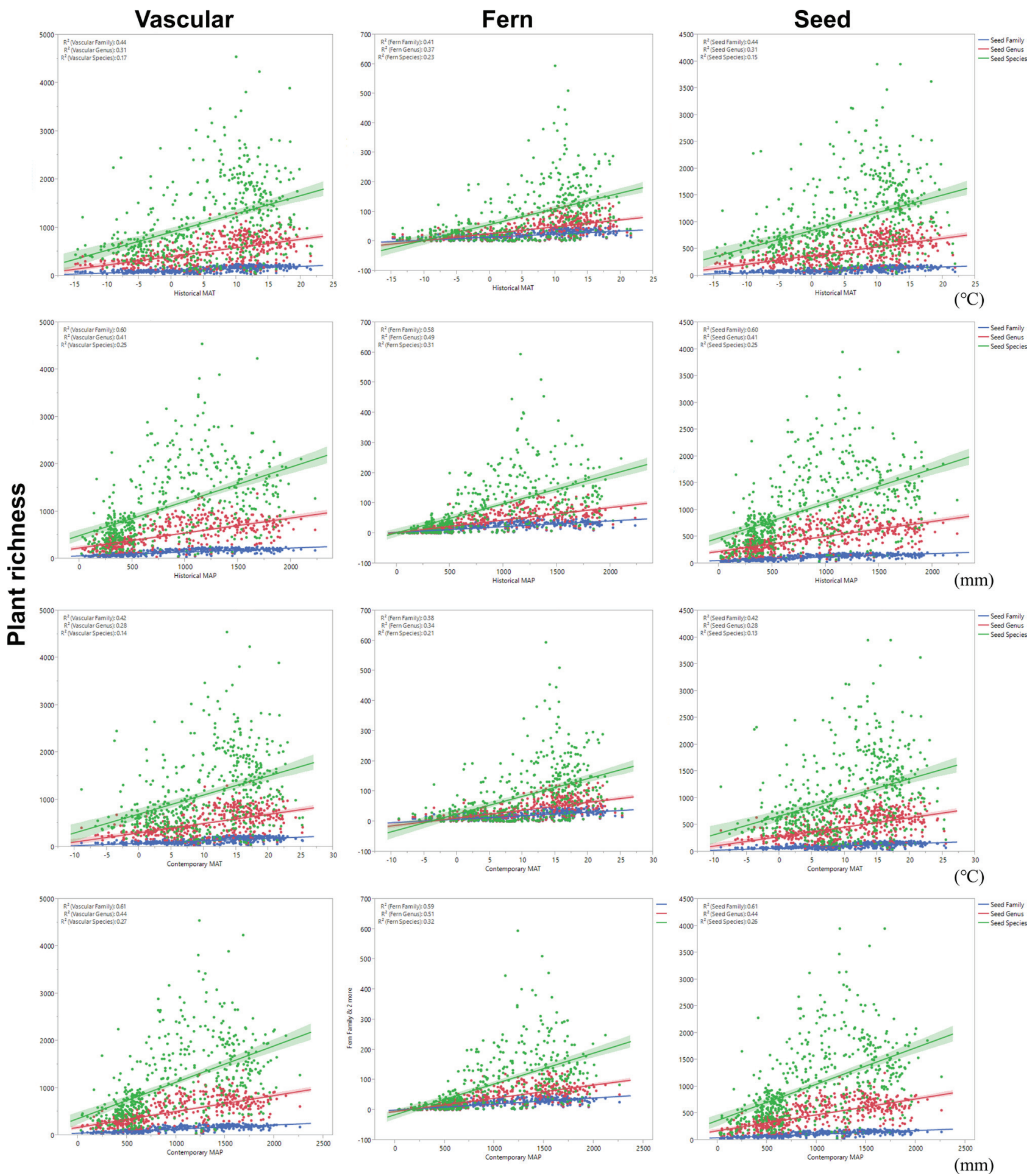

Figure 3. Changes in the large-scale richness of vascular, fern, and seed plants as a function of historical and contemporary climate across different taxonomic levels. The lines associated with the points in each panel indicate the relationships between historical and contemporary climate and plant richness across different taxonomic levels (i.e., family, genus, and species). Shaded areas over the dashed regression lines represent the $95 \%$ confidence interval of the fitted values for each evaluated order. Values of $R^{2}$ represent the adjusted $R_{a d j}^{2}(\%)$ values from the OLS analysis, which indicate the explanatory power of historical and contemporary climate variables in regard to the large-scale distributional pattern of plant richness. We transferred the values of $R_{a d j}^{2}$ to Figure 3 based on the unit "\%". Plant richness represents the number of families, genera, and species. All the $R_{a d j}^{2}(\%)$ values obtained from the OLS analysis were significant $(P<0.05)$. 


\section{Gymnosperm}
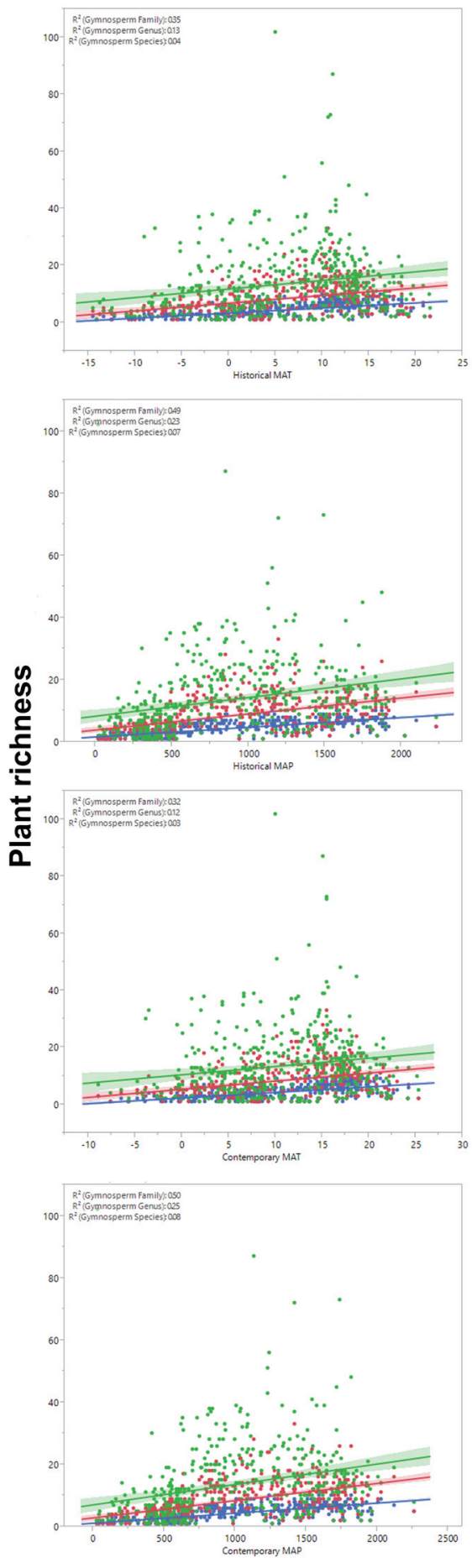

Angiosperm
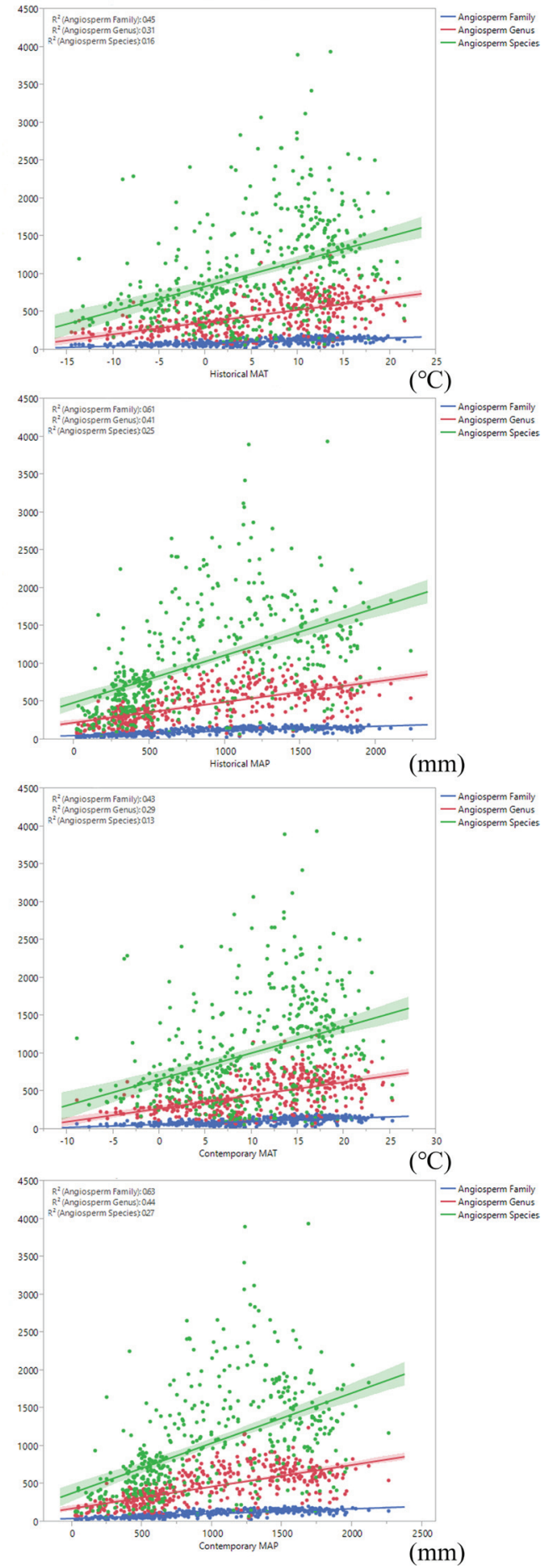

Figure 4. Changes in the large-scale richness of gymnosperm and angiosperm plants as a function of historical and contemporary climate across different taxonomic levels. The lines associated with the points in each panel indicate the relationships between historical and contemporary climate and plant richness across different taxonomic levels (i.e., family, genus, and species). Shaded areas over the dashed regression lines represent the $95 \%$ confidence intervals of the fitted values for each evaluated order. Values of $R^{2}$ represent the adjusted $R_{a d j}^{2}(\%)$ values obtained from the OLS analysis, which indicate the explanatory power of historical and contemporary climates in regard to the large-scale distributional pattern of plant richness. We transferred the values of $R_{a d j}^{2}$ to Figure 4 based on the unit "\%". Plant richness represents the number of families, genera, and species. All the $R_{a d j}^{2}(\%)$ values obtained from the OLS analysis were significant $(P<0.05)$. 
of species (Qian \& Ricklefs 2007, Huang et al. 2016). Furthermore, species' abilities to thrive in an environment, resist and solve physiological problems, interact with other species and influence various ecosystem processes are determined by their functional traits (Díaz \& Cabido 2001, Fonseca \& Ganade 2001, Rosenfeld 2002, Kuebbing et al. 2018). In other words, while some species exhibit uncommon traits (functionally unique species), other species are functionally similar (i.e., represent redundant species) within one specific family (Naeem 1998, Rosenfeld 2002). Hence, the effects of historical and contemporary climate on the large-scale distributional pattern of plant richness were found to be significant at the family level.

Furthermore, other recent environmental variables (e.g., human influences and usage of land) may influence the distributional patterns of plant species richness at large scales (Kier et al. 2005, Gerstner et al. 2014). Such effects may escalate with increases in habitat areas and ranges (Lundholm 2009). The habitat areas and distributional ranges of plants are generally wider at the family level than at the species level (O'Brien et al. 1998, Huang et al. 2016). Therefore, the explanatory power of the historical and contemporary climate in regard to plant richness may rely on changes in taxonomic level (i.e., family, genus, and species) due to changes in habitat areas and distributional ranges.

Our results indicate that the influence of climate on plant richness at large scales differs between non-seed and seed plants (Table 4 and Figure 3). Fossil plant records (e.g., Dubiel 1987, Collinson 2001, 2002, Watkins \& Cardelús 2012, Naugolnykh et al. 2016) indicate that paleoclimates have affected the large-scale distributional pattern of ferns, while current bioclimatic variables, mainly those related to humidity (as water is an essential medium for fern reproduction), are closely associated with the variation in fern community composition. The physiological requirements and relative habitat restrictions of fern plants make them more sensitive to climate change than seed plants, and the effects of climate on plant richness may therefore differ between fern and seed plants (Schneider et al. 2004, Peppe et al. 2014).

We found that the explanatory power of the historical and contemporary climate variables was higher for gymnosperm plant richness than for angiosperm richness (Table 4 and Figure 4). Such variation in explanatory power may be the result of evolutionary history and physiological adaptions to historical and contemporary climate (Wang et al. 2010, Yang et al. 2014, Lu et al. 2018, Xu et al. 2018). For instance, Lu et al. (2018) found that herbaceous plants usually have higher molecular substitution rates than woody plants, partly due to their shorter generation times, apparently enabling herbaceous species in China to adapt quickly in response to climate change through increased genetic divergence and higher speciation rates.

Environmental heterogeneity and precipitation are the most important predictors of the diversity patterns of gymnosperms, followed by historical temperatures (Lü et al. 2018). A number of gymnosperm plants are distributed mainly in western China (Lü et al. 2018), and there is a large difference in historical temperature and contemporary precipitation be- tween eastern and western China (Qin et al. 2015, Lu et al. 2018, Lü et al. 2018). Furthermore, the temperature sensitivity of spring tree growth, water use, and successional strategies vary dramatically between the dominant angiosperm and gymnosperm plants (Bond 1989, Ma et al. 2016, Wan et al. 2017, Trugman et al. 2018). The differences in the variables correlated with plant richness between gymnosperm and angiosperm plants may be related to their evolutionary histories and physiological adaptions to historical temperature and contemporary precipitation (Lu et al. 2018, Lü et al. 2018). Hence, historical and contemporary climate influence the large-scale distributional patterns of gymnosperm and angiosperm plant richness to different extents.

Our study used protected area data to explore the effects of historical and contemporary climate on the largescale distributional patterns of plant richness across different taxonomic levels, contributing to the conservation of plant diversity in China. China is the country/territory on Earth experiencing the greatest degree of land transformation (Liu et al. 2003, López-Pujol et al. 2006, Zhang et al. 2017). Based on our results that the historical climate can shape the large-scale distributional pattern of plant richness, we predict that it will take a long time for the plant diversity in China to recover if the plant richness is damaged. Furthermore, it will be necessary to use large-scale data from protected areas to assess the effects of climate change on plant diversity in protected areas around the world (Araújo et al. 2011, Wan et al. 2014, Keppel et al. 2015, Wan et al. 2018). Thus, plant diversity data from protected areas could be beneficial not only for scientists but also for decision makers and practitioners in other fields (Araújo et al. 2011, Wan et al. 2016, Zhang et al. 2017). Hence, future studies should pay attention to the strategic value of different protected areas in the context of the plant diversity they protect, especially considering the current trends of land transformation around the world.

In conclusion, the distributional patterns of plant richness at large scales could be predicted across different taxonomic levels after the assessment of paleoclimate and contemporary climate data. Pleistocene temperature and current precipitation effects were studied to understand plant richness patterns, and such effects were found to be most important at the family level. In particular, the historical and contemporary climate data were better correlated with fern plant richness than with seed plant richness. Understanding the effects of historical and contemporary climate on the largescale distributional patterns of plant richness across various taxonomic levels may help guide predictions of future plant diversity and facilitate the conservation of plant diversity under climate change.

\section{Acknowledgements}

Many thanks are due to the editor and two reviewers for their useful and constructive comments, which helped improve an earlier version of our manuscript. This work was supported by the National Natural Science Foundation of China (NSFC; 31800449 and 31800464 ), the Basic Research 
Project of Qinghai Province, China (2019-ZJ-936Q), and the Fondecyt project (3190073 and 3180028).

\section{Literature cited}

Araújo MB, Alagador D, Cabeza M, Nogués-Bravo D, Thuiller W. 2011. Climate change threatens European conservation areas. Ecology Letters 14: 484-492.

DOI: https://doi.org/10.1111/j.1461-0248.2011.01610.x

Barnosky AD, Lindsey EL, Villavicencio NA, Bostelmann E, Hadly EA, Wanket J, Marshall CR. 2016. Variable impact of late-Quaternary megafaunal extinction in causing ecological state shifts in North and South America. Proceedings of the National Academy of Sciences 113: 856-861.

DOI: https://doi.org/10.1073/pnas.1505295112

Blonder B, Enquist BJ, Graae BJ, Kattge J, Maitner BS, Morueta-Holme N, Ordonez A, Śímová I, Singarayer J, Svenning J, Valdes PJ, Violle C. 2018. Late Quaternary climate legacies in contemporary plant functional composition. Global Change Biology 24: 4827-4840.

DOI: https://doi.org/10.1111/gcb.14375

Bond WJ. 1989. The tortoise and the hare: ecology of angiosperm dominance and gymnosperm persistence. Biological Journal of the Linnean Society 36: 227-249.

DOI: https://doi.org/10.1111/j.1095-8312.1989.tb00492.x

Boyce CK, Lee JE. 2017. Plant evolution and climate over geological timescales. Annual Review of Earth and Planetary Sciences 45: 61-87.

DOI: https://doi.org/10.1146/annurev-earth-063016-015629

Brunsdon C, Fotheringham AS, Charlton ME. 1996. Geographically weighted regression: a method for exploring spatial nonstationarity. Geographical Analysis 28: 281-298. DOI: https://doi.org/10.1111/j.1538-4632.1996.tb00936.x

Colinvaux PA, De Oliveira PE. 2001. Amazon plant diversity and climate through the Cenozoic. Palaeogeography, Palaeoclimatology, Palaeoecology 166: 51-63. DOI: https://doi.org/10.1016/s0031-0182(00)00201-7

Collinson ME. 2001. Cainozoic ferns and their distribution. Brittonia 53: 173-235.

DOI: https://doi.org/10.1007/bf02812700

Collinson ME. 2002. The ecology of Cainozoic ferns. Review of Palaeobotany and Palynology 119: 51-68. DOI: https://doi.org/10.1016/s0034-6667(01)00129-4

Cotton JM, Cerling TE, Hoppe KA, Mosier TM, Still CJ. 2016. Climate, $\mathrm{CO}_{2}$, and the history of North American grasses since the Last Glacial Maximum. Science Advances 2: e1501346. DOI: https://oi.org/10.1126/sciadv.1501346

Díaz S, Cabido M. 2001. Vive la difference: plant functional diversity matters to ecosystem processes. Trends in Ecology \& Evolution 16: 646-655.

DOI: https://doi.org/10.1016/S0169-5347(01)02283-2

Diniz-Filho JAF, Bini LM, Hawkins BA. 2003. Spatial autocorrelation and red herrings in geographical ecology. Global Ecology and Biogeography 12: 53-64.

DOI: https://doi.org/10.1046/j.1466-822X.2003.00322.x

Dubiel RF. 1987. Sedimentology of the Upper Triassic Chinle Formation, southeastern Utah: paleoclimatic implications. Journal of the Arizona-Nevada Academy of Science 22: 35-
45. DOI: https://www.jstor.org/stable/40024382

Eiserhardt WL, Bjorholm S, Svenning JC, Rangel TF, Balslev H. 2011. Testing the water-energy theory on American palms (Arecaceae) using geographically weighted regression. PLOS One 6: e27027.

DOI: https://doi.org/10.1371/journal.pone.0027027

Fang J, Wang Z, Tang Z, Brown JH. 2012. Large-scale patterns of tree species richness and the metabolic theory of ecology. Global Ecology and Biogeography 21: 508-512. DOI: https://doi.org/10.1111/j.1466-8238.2011.00688.x

Feng G, Mao L, Benito BM, Swenson NG, Svenning JC. 2017. Historical anthropogenic footprints in the distribution of threatened plants in China. Biological Conservation 210: 3 8. DOI: https://doi.org/10.1016/j.biocon.2016.05.038

Fonseca CR, Ganade G. 2001. Species functional redundancy, random extinctions and the stability of ecosystems. Journal of Ecology 89: 118-125.

DOI: https://doi.org/10.1046/j.1365-2745.2001.00528.x

Foody GM. 2004. Spatial nonstationarity and scale-dependency in the relationship between species richness and environmental determinants for the sub-Saharan endemic avifauna. Global Ecology and Biogeography 13: 315-320.

DOI: https://doi.org/10.1111/j.1466-822X.2004.00097.x

Gerstner K, Dormann CF, Stein A, Manceur AM, Seppelt R. 2014. Effects of land use on plant diversity-A global metaanalysis. Journal of Applied Ecology 51: 1690-1700. DOI: https://doi.org/10.1111/1365-2664.12329

Huang J, Lu X, Huang J, Ma K. 2016. Conservation priority of endemic Chinese flora at family and genus levels. Biodiversity and Conservation 5: 23-35.

DOI: https://doi.org/10.1007/s10531-015-1027-0

Keppel G, Mokany K, Wardell-Johnson GW, Phillips BL, Welbergen JA, Reside AE. 2015. The capacity of refugia for conservation planning under climate change. Frontiers in Ecology and the Environment 13: 106-112.

DOI: https://doi.org/10.1890/140055

Kier G, Mutke J, Dinerstein E, Ricketts TH, Küper W, Kreft H, Barthlott W. 2005. Global patterns of plant diversity and floristic knowledge. Journal of Biogeography 32: 1107-1116. DOI: https://doi.org/10.1111/j.1365-2699.2005.01272.x

Kraft NJ, Godoy O, Levine JM. 2015. Plant functional traits and the multidimensional nature of species coexistence. Proceedings of the National Academy of Sciences 112: 797-802. DOI: https://doi.org/10.1073/pnas.1413650112

Kreft H, Jetz W. 2007. Global patterns and determinants of vascular plant diversity. Proceedings of the National Academy of Sciences 104: 5925-5930.

DOI: https://doi.org/10.1073/pnas.0608361104

Kuebbing SE, Maynard DS, Bradford MA. 2018. Linking functional diversity and ecosystem processes: A framework for using functional diversity metrics to predict the ecosystem impact of functionally unique species. Journal of Ecology 106: 687-698. DOI: https://doi.org/10.1111/1365-2745.12835

Lawrence DM, Oleson KW. 2012. The CCSM4 land simulation, 1850-2005: Assessment of surface climate and new capabilities. Journal of Climate 25: 2240-2260.

DOI: https://doi.org/10.1175/JCLI-D-11-00103.1

Lister AM. 2004. The impact of Quaternary ice ages on mam- 
malian evolution. Philosophical Transactions of the Royal Society B: Biological Sciences 359: 221-41.

DOI: https://doi.org/10.1098/rstb.2003.1436

Liu J, Ouyang Z, Pimm SL, Raven PH, Wang X, Miao H, Han N. 2003. Protecting China's biodiversity. Science 300: 12401241. DOI: https://doi.org/10.1126/science.1078868

Liu Y, Su X, Shrestha N, Xu X, Wang S, Li Y, Wang Q, Sandanov, Wang Z. 2018. Effects of contemporary environment and Quaternary climate change on drylands plant diversity differ between growth forms. Ecography 42: 334-345. DOI: https://doi.org/10.1111/ecog.03698

López-Pujol J, Zhang FM, Ge S. 2006. Plant biodiversity in China: richly varied, endangered, and in need of conservation. Biodiversity and Conservation 15: 3983-4026. DOI: https://doi.org/10.1007/s10531-005-3015-2

Lu LM, Mao LF, Yang T, Ye JF, Liu B, Li HL, Sun M, Miller JT, Mathews S, Hu HH, Niu YT, Peng DX, Chen YH, Smith SA, Chen M, Xiang KL, Le CT, Dang VC, Lu AM, Soltis PS, Soltis DE, Li JH, Chen ZD. 2018. Evolutionary history of the angiosperm flora of China. Nature 554: 234-238. DOI: https://doi.org/10.1038/nature25485

Lundholm JT. 2009. Plant species diversity and environmental heterogeneity: spatial scale and competing hypotheses. Journal of Vegetation Science 20: 377-391.

DOI: https://doi.org/10.1111/j.1654-1103.2009.05577.x

Lü L, Cai H, Yang Y, Wang Z, Zeng H. 2018. Geographic patterns and environmental determinants of gymnosperm species diversity in China. Biodiversity Science 26: 1133-1146. DOI: https://doi.org/10.17520/biods.2018098

Ma Z, Sandel B, Svenning JC. 2016. Phylogenetic assemblage structure of North American trees is more strongly shaped by glacial-interglacial climate variability in gymnosperms than in angiosperms. Ecology and Evolution 6: 3092-3106. DOI: https://doi.org/10.1002/ece3.2100

Mellin C, Mengersen K, Bradshaw CJA, Caley MJ. 2014. Generalizing the use of geographical weights in biodiversity modelling. Global Ecology and Biogeography 23: 13141323. DOI: https://doi.org/10.1111/geb.12203

Millar TR, Heenan PB, Wilton AD, Smissen RD, Breitwieser I. 2017. Spatial distribution of species, genus and phylogenetic endemism in the vascular flora of New Zealand, and implications for conservation. Australian Systematic Botany 30: 134-147. DOI: https://doi.org/10.1071/sb16015

Naeem S. 1998. Species redundancy and ecosystem reliability. Conservation Biology 12: 39-45.

DOI: https://doi.org/10.1111/j.1523-1739.1998.96379.x

Nagelkerke NJ. 1991. A note on a general definition of the coefficient of determination. Biometrika 78: 691-692. DOI: https://doi.org/10.2307/2337038

Naugolnykh SV, Wang L, Han M, Jin JH. 2016. A new find of the fossil Cyclosorus from the Eocene of South China and its paleoclimatic implication. Journal of Plant Research 129: 3-12. DOI: https://doi.org/10.1007/s10265-015-0765-0

Normand S, Ricklefs RE, Skov F, Bladt J, Tackenberg O, Svenning JC. 2011. Postglacial migration supplements climate in determining plant species ranges in Europe. Proceedings of the Royal Society B: Biological Sciences 278: 3644-3653. DOI: https://doi.org/10.1098/rspb.2010.2769
O'Brien EM. 1998. Water-energy dynamics, climate, and prediction of woody plant species richness: an interim general model. Journal of Biogeography 25: 379-398.

DOI: https://doi.org/10.1046/j.1365-2699.1998.252166.x

O'Brien EM, Whittaker RJ, Field R. 1998. Climate and woody plant diversity in southern Africa: relationships at species, genus and family levels. Ecography 21: 495-509. DOI: https://doi.org/10.1111/j.1600-0587.1998.tb00441.x

Peppe DJ, Lemons CR, Royer DL, Wing SL, Wright IJ, Lusk CH, Rhoden CH. 2014. Biomechanical and leaf-climate relationships: a comparison of ferns and seed plants. American Journal of Botany 101: 338-347.

DOI: https://doi.org/10.3732/ajb.1300220

Petchey OL, Gaston KJ. 2002. Functional diversity (FD), species richness and community composition. Ecology Letters 5: 02411. DOI: https://doi.org/10.1046/j.1461-0248.2002.00339.x

Petchey OL, Gaston KJ. 2006. Functional diversity: back to basics and looking forward. Ecology Letters 9: 741-758. DOI: https://doi.org/10.1111/j.1461-0248.2006.00924.x

Pimm SL, Joppa LN. 2015. How many plant species are there, where are they, and at what rate are they going extinct? Annals of the Missouri Botanical Garden 100: 170-176. DOI: https://doi.org/10.3417/2012018

Prinzing A. 2001. The niche of higher plants: evidence for phylogenetic conservatism. Proceedings of the Royal Society B: Biological Sciences 268: 2383-2389.

DOI: https://doi.org/10.1098/rspb.2001.1801

Qin D, Ding Y, Mu M. 2015. Climate and environmental change in China: 1951-2012. Gernman: Springer. eISBN 978-3-66248482-1

Qian H, Ricklefs RE. 2007. A latitudinal gradient in large-scale beta diversity for vascular plants in North America. Ecology Letters 10: 737-744.

DOI: https://doi.org/10.1111/j.1461-0248.2007.01066.x

Rangel TF, Diniz-Filho JAF, Bini LM. 2010. SAM: a comprehensive application for spatial analysis in macroecology. Ecography 33: 46-50.

DOI: https://doi.org/10.1111/j.1600-0587.2009.06299.x

Rosenfeld JS. 2002. Functional redundancy in ecology and conservation. Oikos 98: 156-162.

DOI: https://doi.org/10.1034/j.1600-0706.2002.980116.x

Sandel B, Arge L, Dalsgaard B, Davies RG, Gaston KJ, Sutherland WJ, Svenning JC. 2011. The influence of Late Quaternary climate-change velocity on species endemism. Science 334: 660-664. DOI: https://doi.org/10.1126/science.1210173

Schneider H, Schuettpelz E, Pryer KM, Cranfill R, Magallón S, Lupia R. 2004. Ferns diversified in the shadow of angiosperms. Nature 428: 553.

DOI: https://doi.org/10.1038/nature02361

Shrestha N, Wang Z, Su X, Xu X, Lyu L, Liu Y, Dimitrov D, Kennedy JD, Wang Q, Tang Z, Feng X . 2018. Global patterns of Rhododendron diversity: The role of evolutionary time and diversification rates. Global Ecology and Biogeography 27: 913-924. DOI: https://doi.org/10.1111/geb.12750

Svenning JC. 2003. Deterministic Plio-Pleistocene extinctions in the European cool-temperate tree flora. Ecology Letters 6: 646-653.

DOI: https://doi.org/10.1046/j.1461-0248.2003.00477.x 
Svenning JC, Sandel B. 2013. Disequilibrium vegetation dynamics under future climate change. American Journal of Botany 100: 1266-1286. DOI: https://doi.org/10.3732/ajb.1200469

Svenning JC, Skov F. 2007. Ice age legacies in the geographical distribution of tree species richness in Europe. Global Ecology and Biogeography 16: 234-245. DOI: https://doi.org/10.1111/j.1466-8238.2006.00280.x

Svenning JC, Eiserhardt WL, Normand S, Ordonez A, Sandel B. 2015. The influence of paleoclimate on present-day patterns in biodiversity and ecosystems. Annual Review of Ecology, Evolution, and Systematics 46: 551-572.

DOI: https://doi.org/10.1146/annurev-ecolsys-112414-054314

Tang L, Shao G, Piao Z, Dai L, Jenkins MA, Wang S, Wu G, Wu J, Zhao J. 2010. Forest degradation deepens around and within protected areas in East Asia. Biological Conservation 143: $1295-1298$.

DOI: https://doi.org/10.1016/j.biocon.2010.01.024

Thompson K, Askew AP, Grime JP, Dunnett NP, Willis AJ. 2005. Biodiversity, ecosystem function and plant traits in mature and immature plant communities. Functional Ecology 19: 355-358.

DOI: https://doi.org/10.1111/j.0269-8463.2005.00936.x

Tilman D, Lehman CL, Thomson KT. 1997. Plant diversity and ecosystem productivity: theoretical considerations. Proceedings of the National Academy of Sciences 94: 1857-1861. DOI: https://doi.org/10.1073/pnas.94.5.1857

Trugman AT, Medvigy D, Anderegg WR, Pacala SW. 2018. Differential declines in Alaskan boreal forest vitality related to climate and competition. Global Change Biology 24: 1097-1107. DOI: https://doi.org/10.1111/gcb.13952

Wan JZ, Wang CJ, Yu FH. 2017. Spatial conservation prioritization for dominant tree species of Chinese forest communities under climate change. Climatic Change 144: 303-316. DOI: https://doi.org/10.1007/s10584-017-2044-7

Wan JZ, Wang CJ, Yu FH. 2018. Human footprint and climate disappearance in vulnerable ecoregions of protected areas. Global and Planetary Change 170: 260-268. DOI: https://doi.org/10.1016/j.gloplacha.2018.09.002

Wan J, Wang C, Yu J, Nie S, Han S, Liu J, Zu Y, Wang Q. 2016. Developing conservation strategies for Pinus koraiensis and Eleutherococcus senticosus by using model-based geographic distributions. Journal of Forestry Research 27: 389-400. DOI: https://doi.org/10.1007/s11676-015-0170-5

Wan J, Wang C, Yu J, Nie S, Han S, Zu Y, Chen C, Yuan S, Wang, Q. (2014). Model-based conservation planning of the genetic diversity of Phellodendron amurense Rupr due to

Associated editor: Luis Eguiarte

Author contributions: CJW: writing analysis and compilation of the database; JZW: reviewing our manuscript. climate change. Ecology and Evolution 4: 2884-2900. DOI: https://doi.org/10.1002/ece3.1133

Wang CJ. 2017. Geographical Distribution Pattern and Spatial Conservation Prioritization for Wild Plants in China under Climate Change. Ph.D. thesis, Beijing Forestry University.

Wang Q, Su X, Shrestha N, Liu Y, Wang S, Xu X, Wang Z. 2017. Historical factors shaped species diversity and composition of Salix in eastern Asia. Scientific Reports 7: 42038. DOI: https://doi.org/10.1038/srep42038

Wang Z, Fang J, Tang Z, Lin X. 2010. Patterns, determinants and models of woody plant diversity in China. Proceedings of the Royal Society B: Biological Sciences 278: 2122-2132. DOI: https://doi.org/10.1098/rspb.2010.1897

Wang Z, Fang J, Tang Z, Lin X. 2012. Relative role of contemporary environment versus history in shaping diversity patterns of China's woody plants. Ecography 35: 1124-1133. DOI: https://doi.org/10.1111/j.1600-0587.2011.06781.x

Watkins Jr J, Cardelús CL. 2012. Ferns in an angiosperm world: cretaceous radiation into the epiphytic niche and diversification on the forest floor. International Journal of Plant Sciences 173: 695-710. DOI: https://doi.org/10.1086/665974

White HJ, Montgomery WI, Pakeman RJ, Lennon JJ. 2018. Spatiotemporal scaling of plant species richness and functional diversity in a temperate semi-natural grassland. Ecography 41: 845-856. DOI: https://doi.org/10.1111/ecog.03111

Xu W, Svenning JC, Chen G, Chen B, Huang J, Ma K. 2018. Plant geographical range size and climate stability in China: Growth form matters. Global Ecology and Biogeography 27: 506-517. DOI: https://doi.org/10.1111/geb.12710

Xu X, Wang Z, Rahbek C, Sanders NJ, Fang J. 2016. Geographical variation in the importance of water and energy for oak diversity. Journal of Biogeography 43: 279-288. DOI: https://doi.org/10.1111/jbi.12620

Yang H, Li Y, Wu M, Zhang ZHE, Li L, Wan S. 2011. Plant community responses to nitrogen addition and increased precipitation: the importance of water availability and species traits. Global Change Biology 17: 2936-2944.

DOI: https://doi.org/10.1111/j.1365-2486.2011.02423.x

Yang W, Ma K, Kreft H. 2014. Environmental and socio-economic factors shaping the geography of floristic collections in China. Global Ecology and Biogeography 23: 1284-1292. DOI: https://doi.org/10.1111/geb.12225

Zhang L, Luo Z, Mallon D, Li C, Jiang Z. 2017. Biodiversity conservation status in China's growing protected areas. Biological Conservation 210: 89-100.

DOI: https://doi.org/10.1016/j.biocon.2016.05.005

\section{Supplementarv material}

Data on plant richness, mean annual temperature (MAT; ${ }^{\circ} \mathrm{C}$ ) and mean annual precipitation (MAP; mm). The data on plant richness refer to different taxonomic levels (i.e., family, genus, and species) based on the vascular, fern, seed, gymnosperm, and angiosperm plant groups. 